\title{
Problems in the Use of World Prices in Social Cost-Benefit Analysis: Some Experiences from a Study in Pakistan
}

\section{John Weiss}

Since economists started to write on the problems of developing countries it has been common practice to question the validity of domestic market prices in these economies as indicators of social value. It was not until the middle 1960s, however, that rules were put forward to construct a comprehensive set of shadow or accounting prices which for the purposes of project analysis would replace prices actually observed in the market. These shadow prices were felt to be comprehensive in that they were to cover all the major commodities in the economy, and to allow for a number of different government objectives in the definition of social value. The major works in this field were Little-Mirrlees $(1968 ; 1974)$ and UNIDO (1972).

When these studies first appeared differences of emphasis and the use of different units of account may have given the impression that differences of substance existed between the two approaches. Recent work, however, has illustrated their similarity and a number of studies have appeared which stress the basic unity of the main social cost-benefit analysis (SCBA) literature (Lal 1974; Squire and van der Tak 1975; Bruce 1976).

A number of case-studies using SCBA have also been published (Lal 1975; Scott, MacArthur and Newbery 1976; Little and Scott 1976; Linn 1977). These illustrate some of the problems involved in applying the methodology in practice. Stewart (1978) gives a critical survey of many of these published case-studies. The present author has been involved recently in a research project to produce estimates of shadow prices for Pakistan, and to apply these in an analysis of three industrial projects. The final results of the study are unlikely to be available before mid-1978; however this paper raises a number of issues, suggested by the preliminary results. These relate to the shadow pricing methodology employed, and in particular stress the way in which a crude average parameter had to be employed despite attempts at greater sophistication.

\section{Use of conversion factors in SCBA}

A distinction basic to SCBA is that between internationally traded goods and non-traded goods. Traded goods are those whose use or production by a project has its main effect, either directly or indirectly, upon the balance of payments, rather than on domestic production. The world prices of these goods, either cif or fob, are taken to be a measure of their value to the economy, and therefore the basis of their shadow prices.

In all economies, however, there will be a significant number of commodities whose use or production in projects will have its major impact upon the domestic economy.

These are non-traded goods; examples are commodities whose physical nature prevents their entry into world trade, such as construction, power, and transport activities; commodities for which there is no world market as far as the economy under consideration is concerned; and commodities which are rendered non-traded as a result of government restrictions on trade. The normal recommendation for the shadow price of these non-traded items is to base it upon the social costs of their production.

Before the development of systematic discussions on SCBA it was common procedure.

- to use the domestic market price as the shadow price of a non-traded good;

-to use the world price of a traded good as its shadow price;

- to convert the shadow price of the traded good into a domestic price equivalent using a shadow exchange rate (SER).

The SER was used to reflect more accurately the value to the economy of an extra unit of foreign exchange; an estimate for the SER was often based on the weighted average ratio of domestic to world prices for a range of comparable goods. The more recent developments in SCBA have stressed the crudeness of this procedure (LittleMirrlees 1968, 1974; Scott 1974).

The argument can be illustrated with a simple example; one may have three goods, a traded 
good A valued at $\$ 10$, and two non-traded goods, $B$ and $C$ both priced at Rs. 100 domestically. If the official exchange rate is Rs. 10 per $\$$, and the SER is Rs. 13 per $\$$, the above procedure would value $A$ at Rs. 130 and $B$ and $C$ at Rs. 100. The problem is that the SER is an average relationship which gives the average value of a dollar; additional dollars will be utilized in various ways however, and the value of a marginal dollar may differ considerably from this average value.

Little-Mirrlees put forward the alternative approach of expressing all shadow prices in terms of world price values. This meant estimating the costs of producing all non-traded goods in world prices. In principle one can break down inputs used in the production of non-traded goods into traded goods and domestic factors; therefore by valuing domestic factors in terms of world prices one can produce world price equivalent values, as shadow prices for non-traded goods. The ratio of the shadow price of a good to its domestic price is termed a conversion factor, and in theory the new SCBA methodology requires the calculation of specific conversion factors for all the non-traded goods in the economy.

This can be illustrated by reference to the example used above; good A will be valued at its world price of $\$ 10$ which can be converted into local currency at the official exchange rate. The costs in world prices of producing goods B and C domestically must be calculated for both products; if the conversion factor for $\mathrm{B}$ is 0.8 , and for $\mathrm{C}$ is 0.7 , this means that the relative shadow prices, using the new method would be Rs. 100 for A, Rs. 80 for B and Rs. 70 for C.

In practice data may not be available at the degree of disaggregation necessary to estimate production costs in world price terms for large numbers of non-traded goods. In these circumstances it is necessary to resort to an average conversion factor which expresses an average relationship between world and domestic prices. The Standard Conversion Factor (SCF) is intended as a measure of the world price value of an average unit of domestic expenditure; therefore in the absence of more detailed data it can be used to express the world price equivalent of a non-traded item. The SCF can be calculated in two ways; first, where a large number of conversion factors are already available for both traded and non-traded goods, the SCF can be taken as the average of these (Scott, MacArthur and Newbery 1976). Alternatively, where a detailed set of shadow prices and conversion factors are not available the SCF can be calculated from a formula based on the average rate of import duty and export tax (Squire and van der Tak 1975, Bruce 1976, Linn 1977). The formula is:

$$
S C F=\frac{(M+X)}{(M+T m)+(X-T x)}
$$

where: $\mathbf{M}$ is the cif value of visible imports; $X$ is the fob value of visible exports; $\mathrm{Tm}$ is the value of total import duties; Tx is the value of total export taxes minus export subsidies.

The main assumptions behind this formula are that the divergence between domestic and world prices for traded goods is explained solely by import duties and export taxes or subsidies, and that the weighted average divergence for traded goods can be used as a measure of the divergence for all goods in the economy. This formula is simply the reciprocal of the SER as the latter is of ten calculated; the SER compares domestic prices to world prices rather than vice versa. It is relatively simple to show that an analysis which uses a SCF consistently to value all non-traded goods is equivalent to the procedure of valuing all traded goods at the SER, and all non-traded goods at their domestic price (Weiss 1975).

It should be stressed that frequent use of conversion factors based on average relationships like the SCF is not recommended in the literature; it is suggested that the SCF be used only for minor non-traded goods, and items for which detailed information is lacking. However, many published case-studies have had to rely significantly upon a SCF (Stewart 1978), and this was the experience of the Pakistan study.

\section{Use of SCF in the Pakistan study}

The SCF was used in 3 different ways:

1. It proved very difficult to estimate the cost of major non-traded goods in world price terms. It is normally suggested that input-output data can be used to establish the input composition of non-traded sectors. A revised input-output table was available for Pakistan for $1969 / 70$, which disaggregated the economy into 33 sectors. The data were difficult to use, however. First there was a problem in identifying relevant world prices for some of the tradable inputs used in the production of non-tradables; this was due to the level of aggregation at which the inputs were identified. Secondly, a high proportion of the gross value of output of the non-traded sectors was domestic value added. In the absence of more detailed information this domestic value added had to be revalued in terms of world prices by the SCF. The resulting shadow prices for non-traded goods 
were therefore highly dependent upon the SCF; for example, in the analysis of the construction sector, inputs, comprising only 25 per cent of the gross value of output could be revalued through a direct comparison between world and domestic prices. In the case of the domestic trade sector as much as 95 per cent of the gross value of output was domestic value added. Only two specific conversion factors not dependent upon the SCF could be calculated; one was for the road transport sector, for which alternative cost estimates were available at a more disaggregated level than those contained in the input-output table. The other conversion factor was for locally produced capital equipment; this was based on the weighted average rate of import duty on equipment imports. All other non-traded goods had to be valued using the SCF, since the specific conversion factors which could be calculated for them were either unreliable or very close to the SCF.

2. A cost item which is identified in SCBA as an important element in the shadow wage is the social cost of the additional consumption of unskilled workers employed on a project. This extra consumption must be expressed in terms of world prices, and this is done through the application of a consumption conversion factor, which is a weighted ratio of world to domestic prices for consumer goods. Consumption conversion factors were calculated for different groups of workers in Pakistan; these were also highly dependent upon the value of the SCF. This was partly because many of the goods consumed by unskilled workers were non-traded; another reason, however, was that even for many of those goods which were clearly tradable internationally it was difficult to identify a relevant world market price.

Three categories of traded consumption goods were distinguished. The first were those for which a direct comparison between world and domestic prices was relatively straightforward since the goods involved were relatively homogeneous; examples of these were wheat, rice and sugar. The second category were those where the final goods consumed domestically by unskilled workers differed in form from those traded internationally; this was chiefly because the final product contained significant elements of domestic value added. Examples of these were tea, which is imported raw into Pakistan and packed and blended locally, and tobacco, which is exported raw and made locally into cigarettes. The third category covered the case where items consumed locally differed signficantly in quality from those sold abroad.

Cotton textile items were the most obvious example, since the textile products purchased by unskilled workers were unlikely to be of a design or quality suitable for sale on the world market.

A direct price comparison could only be undertaken for the first category of traded consumer goods. These goods comprised $15-25$ per cent of the total consumption expenditure depending on the income level of the group involved. All other consumption items had to be valued at the SCF.

3. The discount rate used in SCBA appraisals is normally taken to be the rate of return on the marginal public sector project. This must be expressed in world prices, in the same way as all other values in the analysis. In theory it is possible to estimate the return on marginal investment directly in world prices; where this is not possible, however, it is common to revalue an estimate of internal rate of return in domestic prices on the marginal public sector project by the SCF to make the conversion into world price terms (Bruce 1976, Linn 1977). This approach had to be followed in the Pakistan Study. More precisely, the internal rate of return ratio was multiplied by the SCF and divided by a weighted average of the SCF and the capital equipment conversion factor. The weighted average was used to take advantage of the availability of a specific conversion factor which had been calculated for capital equipment.

\section{Problems in the estimation of the SCF}

The SCF was estimated using the simple formula given above; a number of problems were encountered in applying this formula, however:

1. As mentioned earlier the formula assumes that the divergence between domestic and world prices for traded goods is determined solely by the taxes on international trade. However, where quantitative import controls are in force one would expect additional scarcity premia to accrue to importers. Tariffs are the main form of import controls used in Pakistan at present, although quantitative restrictions are also imposed on some import items. The omission of the price markup resulting from these restrictions will impart an upward bias to the SCF estimates.

2. The SCF required in a SCBA should be a forecast value which takes into account a changing composition of imports and exports, and changing government policy towards trade. The use of an average value derived from past values of the SCF for a number of years may be misleading; to cover this problem an attempt was made to produce a forecast value based on commodity projections of imports and exports over the period 1976-81. 
3. The SCF formula assumes that an additional unit of domestic expenditure will both increase imports and divert goods from the export market, in proportion to the current share of different goods in a country's total trade. It is likely however, that certain commodities will be produced primarily for the export market, and that extra domestic expenditure will have little or no impact on the level of their exports; particular cotton textile exports from Pakistan may be an example of this. Alternative estimates of the SCF were produced which allowed for this non-diversion of particular export items; in all cases, allowing for this effect produced a lower value for the SCF than that derived from the main formula.

4. In theory, since the SCF is intended as a measure of the average divergence of domestic from world prices for the economy, nontraded goods should be included in the price comparison. This is only possible where large numbers of conversion factors are available (Scott, MacArthur, and Newbery 1976). We have seen some of the problems involved in providing world price equivalent values for non-traded goods in Pakistan. However, the average relationship provided by the SCF may be misleading since it is based only on a price comparison of traded goods.

These problems mean that considerable uncertainty surrounds the real value of the $\mathrm{SCF}$, despite its important role in the analysis. 0.85 was used as the most likely value. However, it appeared desirable to use sensitivity analysis with alternative high and low values, of 0.9 and 0.8 .

\section{Conclusion}

The new SCBA methodology attempts to base all shadow prices on world market prices; this is to avoid the use of domestic prices as a measure of the value of non-traded goods, and the application of a single SER to convert world market values into domestic terms. The difficulty of working with world market prices for certain traded goods has been pointed out recently (Guisinger and Papageorgiou, 1976). The preliminary results of this work in Pakistan suggest additional problems; first, the difficulty in estimating the cost in terms of world prices of many non-traded goods, and secondly, the difficulty of obtaining comparable world prices for many goods that are consumed domestically, particularly by low income groups. The existence of these problems necessitated the frequent use of the SCF; this was despite the limited role this parameter is given in the main literature and the difficulties which surround its estimation.

An implication of this is that unless the data situation is considerably better than in Pakistan, future SCBA studies will still have to rely significantly upon average relationships like the SCF or SER. Therefore, attention could be usefully directed on means of improving estimates of these average parameters.

\section{Books received}

P. Bradley, C. Raynaut and J. Torrealba, The Guidimaka Region of Mauritania, War on Want, London, 1977

GATT, No 5, Geneva, November, 1977

Roger Plant, Guatemala: Unnatural Disaster, The Latin American Bureau, London, 1978

David Dalby, R. J. Harrison Church and Fatima Bezzas (eds.), Drought in Africa, African Environment Special Report 6, International African Institute, 1978

Worldwatch Paper, Nos 1, 5, 9, Worldwatch Institute, Washington DC

Boris Maldant, Les facteurs de la Production Agricole en Côte d'Ivoire, Institut d'étude du développement, Paris, 1977
Arthur S. Walford, Handbook for Co-operative Personnel, Occasional Paper No. 43, The Plunkett Foundation for Co-operative Studies, Oxford, 1977

Peter C. W. Gutkind, Bibliography on Unemployment, with Special Reference to Africa, McGill University Montreal, 1978

Canada North South, Vol. 2, 'Third World Deficits and the 'Debt Crisis',' The North-South Institute, Ottawa, 1977

Canada North South, Vol. 4, 'World Food and the Canadian 'Breadbasket', 'The North-South Institute, Ottawa, 1978

Papua New Guinea: Its Economic Situation and Prospects for Development, A World Bank Country Economic Report, Johns Hopkins University Press, Baltimore, 1978

The Greek Review of Social Research, Athens, 1977 